\title{
Information sharing online: a research challenge
}

\section{Sheizaf Rafaeli* and Daphne R. Raban}

Center for the Study of the Information Society

University of Haifa, Mount Carmel, Haifa 31905

E-mail: Sheizaf@rafaeli.net_E-mail: draban@univ.haifa.ac.il

*Corresponding author

\begin{abstract}
We view information sharing as a promising target of research. technology and human practice have been evolving toward more opportunities and varied manners in which information can be shared. We propose that 'information sharing' is best understood as a continuum that concomitantly reflects behavioural, social, economic, legal, and technological influences. 'Information' is a hybrid of both 'public' and 'private' goods. The mechanisms that enable, predict, and catalyse sharing behaviour in online contexts should be of major interest to both scholars and practitioners of knowledge systems. We cite a spectrum of analytical as well as empirical research on the topic of sharing, identifying the methods and theories used in the approaches to date. We also review the major online technology genres of import for sharing. We suggest an initial map of constructs to chart future research on sharing.
\end{abstract}

Keywords: information sharing; public goods; disintermediation; lurking; free riding; ownership; free information; commons; information system structure and process.

Reference to this paper should be made as follows: Rafaeli, S. and Raban, D.R. (2005) 'Information sharing online: a research challenge', Int. J. Knowledge and Learning, Vol. 1, Nos. 1/2, pp.62-79.

Biographical notes: Sheizaf Rafaeli obtained his $\mathrm{PhD}$ in 1985 from Stanford University. He is Director of the Center for the Study of the Information Society (http://infosoc.haifa.ac.il) at the Graduate School of Business Administration, University of Haifa, Israel. His interests are in computers as media, value of information, and virtual organisations. He served as co-founder and editor of The Journal of Computer-Mediated Communication. Sheizaf has done research and taught at the Hebrew University of Jerusalem, Technion, University of Michigan, Ohio State, Michigan State, and Stanford Universities. He has been involved in studying and building internet-based activities such as online higher education, journalism, political, governmental, social and economic virtual organisations.

Daphne R. Raban obtained her PhD from University of Haifa, her MSc Technion, and her Bachelor's Degree from Iowa State University. She is a Post Doctoral researcher at the Caesarea Edmond Benjamin de Rothschild Foundation Institute for Interdisciplinary Applications of Computer Science (CRI). She has conducted research and published in the fields of the subjective value of information and information sharing. Daphne has lead an information research and consultancy firm for nine years. 


\section{Introduction}

Acquiring information and knowledge demand many resources. Nevertheless (or maybe as a result), people often share data, content, knowledge, and code. In fact, some identify the act of sharing information as an attribute of humanity itself (Dunbar, 1996). Sharing information is performed regularly, even spontaneously, via formal and informal channels. Information is typically shared face-to-face, in departmental meetings, written reports, telephone conversations, water-cooler meetings, and other traditional forms. It seems that sharing occurs uniquely with information, in ways not replicated with other goods or services. People don't tend to share their possessions, but they do tend to share and expect sharing of information and knowledge. If people are rational and act out of self-interest, why do they share information at all? Is the explanation for information sharing rooted entirely in altruism, or (conversely) are rewards (latent or otherwise) the major engine for information sharing (Ledyard, 1995)? What is the special role of system structure and affordances when information sharing occurs online?

Recent years have seen increased information sharing done via online information systems containing large repositories of information and facilitating interpersonal communications in various forms. Beyond being fast, vast, and cheap, an advantage of online information- and knowledge-sharing is that most interactions are documented. Online documentation provides a means of capturing part of the knowledge transferred in the organisation and is an important part of learning. The success of information systems in supporting and enhancing learning depends largely on psychological and social influences on users. This paper will review the background for the design and implementation of information systems in knowledge sharing and learning environments. We begin by defining the main concepts of information, knowledge, and sharing. We describe some paradoxes that explain the current state of information sharing. The main discussion will focus on theories and methodologies used for researching information sharing and their main findings. We will offer a summary of current knowledge and questions for future research. We will also provide a review of information sharing as currently practised online in a variety of systems.

\section{Definitions}

Three concepts central for this paper are defined as follows:

1 'Information' is data that have been analysed and/or contextualised, carries a message and makes a difference as perceived by the receiver (Ahituv and Neumann, 1986).

2 'Knowledge' or 'expertise' is defined as a human quality that builds on data and information together with experience, values, and insight.

3 'Information sharing' is the act of providing a helpful answer to a request for information.

This very simple definition of information sharing by no means implies that sharing information is a simple issue. Sharing is variable and is subject to attenuation by various environmental influences. Information may be shared in different levels in private and public spaces, at work or nonwork settings, by people from different disciplines and 
depending on the content requested. The quality and reliability of the information shared, and its acceptance, its trust, and willingness to ask for it are all variable too.

In fact, an information-sharing continuum can be envisioned ranging from the free flow of gossip through the moderate flow of knowledge and on to the highly restricted stream of copyrighted information. This continuum would have as prominent milestones on it phenomena such as gag orders, copyright and copyleft, patent law, and Creative Commons (http://creativecommons.org/). The ascendance of the internet and the meteors within it, like Ebay, Amazon and so on, are entirely new and powerful examples of the power of information sharing. Lawrence and Giles (1999), for instance, explain the impact of web-shared academic articles as compared to traditionally published articles. This paper reviews academic research on information sharing, including theories and research methods employed as well as available technologies. The purpose of this review is to offer a broad view of research and offer questions for future research.

\section{Information paradoxes}

Information paradoxes abound. They come from diverse fields such as economics, law, and information technology.

Both information and expertise are multifaceted economic entities. Economically speaking, information is paradoxical. Information, and even more so knowledge, is simultaneously private and public goods. Information bought and sold via market mechanisms coexists with free information and expertise. Both concepts are also 'experience goods', one must experience or use information and knowledge in order to know their value (Shapiro and Varian, 1999). Sharing and trading evidence characteristics of market failure in the sense that information markets for public goods tend to suffer from the 'Tragedy of the Commons' while information markets for private goods tend to develop natural monopolies due to economies of scale, the need for very high initial investment coupled with a marginal cost of virtually zero (Levitan, 1982). Information markets are still trying to adapt and learn ways to survive and flourish in the networked environment. For example, newspapers frequently devise new business models where fresh news is given away for free over the internet, while access to older issues and the archive is a source of revenue. Scientific journals often entertain the reverse policy, where charging only takes place for the freshest of information. On the other hand, archived knowledge and records are made available for free under a variety of innovative models for the distribution and governance of access to scientific content such as the Public Library of Science (Harnad, 1990; Odlyzko, 2001). Do scientific journals suffer from intermediation more than the popular press? Which model will survive? Clearly, public interest and scientific integrity stand to gain or lose from correct choices on this matter. This interface between private (for fee) and public (free) information goods has not received sufficient research attention.

Another seeming paradox is that often 'free' information is used as an enticement to buy service or product. Thus, information products, knowledge, and software are often used as bait (Rafaeli, 1989). Much of the early evolution of the World Wide Web was predicated on this notion. It was interesting to see the vacillations of policy (see, for instance 'The End of Free', chronicling free to fee and beyond, http://www.theendoffree.com). Of course, much of the journalistic practice is 'giving 
away', not 'sharing'. Still, the outcome is that people generally expect more information to be free than is actually available.

From a legal viewpoint there is another seeming paradox. On one hand many legal jurisdictions have rightfully legislated Freedom of Information acts. On the other hand, there are laws protecting and restricting the use of intellectual property. Obviously, both kinds of laws stand to reason. However, to the general public they imply a paradox, pulling in opposing directions. The public will naturally be inclined to expect more freedom implied by law than restrictions. In recent years we hear increasing calls for legislation reform in the perceptions and principles of protecting information, knowledge, and Intellectual Property (IP). The suggested direction is to keep information, knowledge, and IP under stronger controls for shorter periods. Creating this general atmosphere of control is, most likely, inhibitive to the natural tendency to share information.

Sharing is further complicated when considering access to knowledge and information. From a centralised model of information collection, storage, and dissemination by libraries, a completely decentralised environment developed where everyone is, potentially, both a recipient and a contributor of information and knowledge. This change occurred within very few years leaving most online surfers at various stages of their learning curves. The information scene has transformed from a cathedral-like structure to a bazaar (Raymond, 2001). It is tempting to say that being a bazaar, information exchange is egalitarian. However, the study of patterns of information networks reveals that equality and uniformity in access and centrality are not the case at all (Barabasi, 2002; Jones et al., 2004; Ravid and Rafaeli, 2004).

Another change triggered by the ubiquity of information technology and networking is disintermediation - everyone is a user and a publisher, piecing together 'information puzzles' from bits of shared info and other sources. As a result of networking, network effects are added to the evaluation of information. Such effects include the economically familiar "Network Externality" (Shapiro and Varian, 1999) as well as the newly available topology of disintermediation (Rafaeli and Ravid, 2003). More information is available for taking. However, people tend to neglect the opposite of taking, sharing.

The introductory discussion so far leads to an understanding that information or knowledge sharing are not simple. Sharing is not easily explained with economic models that would simply treat information as a commodity. Information sharing is a complex multi-dimensional phenomenon affected by behavioural, social, economic, legal, and technological influences, to name a few. We propose that the simplistic terms 'information sharing' or 'knowledge sharing' are better depicted as a continuum. There are various degrees of freedom from legal, economic and social strings. Each degree of freedom is characterised by a differing inclination to share.

\section{Information-sharing research}

Information sharing is defined as the act of providing a helpful answer to a request for information. Thus, sharing is different from plain posting of information in 'broadcast' mode. Sharing is responsive. It depends on the kindness of peers, friends, or complete strangers or on some intangible reward structure. Since sharing is done mainly by copying and not by a market mechanism involving the transfer of money in exchange for exclusive access to information or expertise, it tends to form a market structure similar to that of public goods. 
Public goods are defined in the Penguin Dictionary of Economics as having three main characteristics:

\begin{abstract}
"The first is that they yield non-rivalrous consumption: one person's use of them does not deprive others from using them. The second is that they are non-excludable - if one person consumes them it is impossible to restrict others from consuming them: public television is non-excludable. Thirdly, public goods are often non-rejectable - individuals cannot abstain from their consumption even if they want to. National defense is a public good of this sort, although television is not. Non-excludability and non-rejectability mean that no market can exist and provision must be made by government, financed by taxation."
\end{abstract}

Looking at the characteristics of information, easy and nearly costless copying, we would tend to think that information is a public good because it fulfills the definitions of jointness of supply and impossibility of exclusion. If information is indeed a public good, it follows that the main impediment to sharing is the 'free riding' phenomenon, a form of social loafing (Karau and Williams, 1993). The analysis presented in the following sections reveals that information is not clearly defined as either a private or a public good. It can be a public good but it may also be a private good, implying different ownership options and various external influences, favouring or inhibiting sharing, are at play. Therefore, information-sharing problems may not be due solely to 'free riding'.

\title{
4.1 Information as a public good
}

Information from various sources can be a public good and be widely shared. For example, information provided by the government can be regarded as a public good. Legislation, such as the Freedom of Information Acts in various countries is usually needed to facilitate the publication of government information. Another form of information as public good is information transmitted via mass media, although individuals can abstain from it and also, funding comes from commercial entities and not from the public itself or government (with the exception of public television and radio). Newer versions of mass media, where many communicate with many, are various kinds of electronic communication means like bulletin boards, chat lines, and many others. These media are also said to be hindered because they are public goods, but, in fact, contributions to them are regular and intensive. It is suggested that interactivity, symmetry, and diversity of content elicit participation (Rafaeli and LaRose, 1993). Academic knowledge may also qualify as a public good as proposed by a recent protest against publishers' stronghold of scientific publishing (http://www.publiclibraryofscience.org/). The academic tradition of information sharing created a public good known as Linux operating system (Raymond, 2001). However, current practices of the academic research market and publishing industry still restrict free public access and usage.

A certain critical mass of contributors and a certain quality level of contributions are vital for the sustenance of a public good (Macy, 1990; Markus, 1990; Rafaeli and LaRose, 1993). Therefore, free-riders and noncontributors threaten the viability of public goods. Broadly characterising the examples given above, it seems that in order for information to become a viable public good, it must have one of the following characteristics: 
- have broad public interest (e.g., news broadcasts, entertainment, etc.)

- be in the public's interest (like scientific discoveries)

- be mandated by legislation (government information)

- have a long tradition of sharing (as in collaborative software development)

- full and balanced disclosure (e.g., academic publications require full research details as well as a complete listing of sources or references).

To what extent do these criteria apply also to information consumed or distributed in organisational settings? The next section describes relevant research findings.

\subsection{Information sharing in organisations}

Much ideology and some research support the notion of information as a public good in the private sector. A pioneering series of experiments on contribution of information to a discretionary database in a business game setting showed that some participants contribute while others free ride (Connolly and Thorn, 1990). These experiments also showed various effects on contribution rates such as asymmetry of costs, value of information, or privatisation. Interestingly, the privatisation experiment used a bidding mechanism and its results exhibited undertrading, meaning that the information provided was valued much higher than information received, although both had identical objective value. Privatisation reduced free riding but did not eliminate it altogether. The authors explained that the root of the problem of undercontribution of information was that discretionary databases are public goods and therefore rational actors will choose to free ride. Privatisation was the recommended solution to overcome the free-rider problem. The experimental set up was such that each participant possessed a single unique and valuable contribution. Naturally, if not everyone contributed, then an undercontribution problem had to arise: The group did not receive all the valuable information possible. This is not necessarily a true reflection of reality. A public good may be produced by the collective action of a critical mass of highly interested and resourceful people (Macy, 1990; Marwell and Oliver, 1993; Constant et al., 1994). Online communities are a typical example of achieving the public good by forming a critical mass.

The pioneering research by Connolly and Thorn (1990) focused on providing input into a public database and did not address the question of sharing information between people in a group. There may be differences in the propensity to share information via databases compared to the propensity to share directly with other people as evidenced by previous research (Sproull et al., 1996). Sharing via databases can be viewed as mediated sharing since the database acts as a medium from which people later retrieve information. People will need communication discipline (Markus, 1990) to proactively contribute, and users will need motivation to initiate a search in the database. In contrast, interpersonal electronic communication means such as e-mail, news groups, etc. provide a direct linkage between people. In these media, people are prompted to participate by reading messages sent by other users or members. Answering a message received from a person asking a question does not require proactive contribution because it is a response. Participation in interpersonal systems is of two main kinds: posting questions or opinions, and offering answers or reactions. In interpersonal systems seeking comes before answering while in database-mediated sharing systems, contributions must precede 
information seeking. It seems reasonable to assume that direct interpersonal communication will prevail over database-mediated sharing when it comes to information sharing. It is not clear which method, database or direct interpersonal communication, prevails for the purpose of seeking information.

The problem of sharing may stem from the medium used rather than from the willingness to share (Dixon, 2000). People may be naturally willing to share information as suggested by Constant et al. $(1994 ; 1996)$ but the effort of using technology to do so may be too great, or the reward may not be apparent due to lack of feedback from the database or from the recipient. This is what makes information sharing in discretionary databases seem like a public good problem: contribution is made to a sort of 'general repository', where the lack of human touch, or feedback, or apparent use, discourages contributions. In systems where information is shared directly among people, a similar problem may arise when contributors, whose contributions are of high quality, will be inundated with more and more requests to share their knowledge, and may see this as a disturbance to their work or even a blunt attempt by free-riders to evade their work. One possible solution that has been suggested is communality, where the public good is not the information itself but the sense of belonging to a community and viewing the community as a source for expert advice (Fulk et al., 1996; Wasco and Faraj, 2000). Communality also suggests that the total sum of contributions is greater than its components thanks to synergy. Different views are expressed or a trend may be observed and so forth. Another solution is assigning a leadership role to one of the participants who will take care of the social management of the group (Butler et al., in press). A group leader is often called the group 'owner.' It is interesting to note that this intuitively assigned semantic title implies increased involvement and contribution. Butler et al. (in press) referred to ownership of the group and the medium where it 'meets', for example an online forum. Ownership of information is ambiguous and may be evenly or unevenly distributed among a group's members. Does even ownership predict more sharing than uneven ownership or, to the contrary, is there more pressure to strive for an ownership equilibrium in a group with uneven information ownership?

Empirical information-sharing research (Constant et al., 1994) using vignettes and attitudes questionnaires explained information sharing by social exchange theory. Social exchange theory predicts sharing based on self-interest and reciprocity. Self-interest was shown to be the main driver for sharing expertise in the study. Expertise was perceived to be privately owned rather than owned by the organisation. Information as product, a computer programme, was perceived to be more organisationally owned. Sharing an organisationally owned information product was found to be mediated by prosocial transformation, people weighed the social good more than their personal benefits. In other words, personal ownership supports sharing more than organisational ownership when it comes to tacit knowledge. This finding is somewhat surprising with respect to the general consensus in the knowledge management literature, which stresses that the main difficulty is sharing tacit knowledge (Davenport and Prusak, 1998). Perhaps this contrast is a manifestation of the lack of motivation to contribute to a database (a knowledge management system) versus the willingness to share information with other people.

Constant et al. (1994) cautioned that sharing attitudes in the case of organisationally owned information may bring about the occurrence of free riding. As prevention, they suggested the public good should be produced by a critical mass of enthusiasts and that organisational culture should promote sharing. Although this sounds reasonable, building on a relatively small group of active participants may be potentially problematic because 
of job mobility and other factors that may cause frequent changes in that core of enthusiasts. Other researchers (Wasco and Faraj, 2000) go a step further suggesting that knowledge should be better managed as a public good causing people to contribute based on moral obligation. Their survey research was done in three programming-related Usenet groups. Programmers have a long cultural tradition of sharing so a preference of the public goods perspective is to be expected from surveying them. Usenet are interorganisational groups so their results, which showed an approximate balance between self-interest and community interest, cannot be directly related to intraorganisational information sharing. Our research showed that motivation for sharing was more intrinsic and relied on subjective preference (Raban, 2004a; 2004b). Sharing based on personal norms and motivation will be more stable than sharing induced by organisational culture.

A survey conducted among university personnel - in order to examine several determinants of information sharing in collaborative electronic media (Jarvenpaa and Staples, 2000) - provided further support for several findings of the previously cited article (Constant et al., 1994). According to the survey, information perceived to be owned by the organisation was less likely to be shared via a collaborative electronic system than privately owned information. The root of this attitude may be in the perception of the source as being public (the organisation) or private (the person). Organisationally owned information may be perceived as part of some 'public domain', therefore there is less need or obligation to share it by a specific person. It may be perceived as widely available, regardless of its objective availability. In addition, knowing they are part of a group of equally knowledgeable peers, people may exhibit a diffusion of responsibility and refrain from sharing (Latane and Darley, 1968; Latane and Rodin, 1969). In fact, experimental work showed this effect in the use of e-mail for requesting help (Barron and Yechiam, 2002). On the other hand, a person who is an expert in his/her field and believes he/she is the only source for particular information may be more willing to share it, knowing that he/she will enjoy personal benefits such as gratitude and improved reputation. Thus an important motivator for information sharing may be personal ownership of information.

Further attention to the question of ownership was given in additional results of the same survey by Jarvenpaa and Staples published in a subsequent paper dealing with antecedents of the ownership perception (Jarvenpaa and Staples, 2001). The authors found a positive association between private and organisational ownership: knowledge workers believed that information products or expertise that they created was owned both by themselves and by the organisation they worked for. The organisation has rights to the products of their work, a research finding that corresponds to the general norm. This finding lends further support to the pro-social transformation that influences employees' perceptions of ownership and sharing behaviour. An interesting point raised by the authors is that organisations should not assume that all information produced by their employees belongs only to the organisation and base their information system design on this wrong assumption. Instead, it is suggested that co-ownership be nurtured.

Information sharing may be affected by a host of additional factors. One such factor may be individual differences in levels of knowledge. It seems reasonable that people who are more knowledgeable and can contribute more also appreciate the information in a collaborative system more than people who are less knowledgeable. Evidence for this is seen in a recent field trial of household computer use where 'gurus' emerged within families, meaning knowledge was not equally acquired by all family members although 
all members had equal access (Kiesler et al., 2000). People who are more knowledgeable also perceive the knowledge as more owned by them personally, and their propensity to share is higher. Having more information to share than others, more knowledgeable people may feel less threatened by sharing since their knowledge supply is not greatly diminished by each act of sharing.

Individual differences arise from subjective measures as well as from knowledge. Klekofski and Heminger (2003) used the theory of reasoned action to show how beliefs and attitudes influenced intentions to share information in an organisational environment, specifically, a government organisation. They found that attitudes and beliefs regarding ownership of information, instrumentality of sharing, and interpersonal feelings all contributed to the intention to share.

Group-level differences explain sharing outcomes by work groups. A recent field study has identified an association between knowledge sharing and performance for structurally diverse groups. Structural diversity was described by geographic location, functional assignment, reporting managers, and business units (Cummings, 2004).

The propensity to share depends on the type of information shared. Sharing is attributed to personal benefits when expertise is shared (Constant et al., 1994; Jarvenpaa and Staples, 2000), and to communality and organisational citizenship and culture when information products are shared (Fulk et al., 1996; Kiesler et al., 2000). Demographic factors were found to contribute to the perception of ownership and propensity to share information in the survey by Jarvenpaa and Staples (2001).

Another factor that is likely to influence sharing is that sharing of information is done by copying. Sharing a copy leaves the originator in his/her original state less the cost of sharing which can reduce, increase, or leave unchanged the value of information. Not losing one's own possession of information seems likely to lower the barrier to information sharing. Still, we know that people do not participate equally in information-sharing activities. Also there are costs associated with sharing such as loss of exclusivity on information and investment of time and effort to share. It seems that some positive motivation is needed beyond the barrier reduction in order to explain sharing. A distinct example for the need to find a better reason to share than the mere lack of costs is the high extent of free riding that was documented for peer-to-peer systems (Adar and Huberman, 2000). The defensive response to perceived free riding might be reduced sharing.

Earlier we presented an analysis of the public goods problem ('the tragedy of the commons') and how it affects information sharing. Then we highlighted research findings on other influences on the tendency to share. The next section discusses why even if information is a public good, this might not necessarily be a problem.

\subsection{Information as a public good - revisited}

In sharing situations, information seems to fulfil mainly the first criterion of public goods. Nonrivalrous consumption is made possible by the technically easy and virtually costless copy-and-distribute capability of digital information. Information does not always meet the other two criteria for public goods, non-excludability and nonrejectability. It is technically easy to exclude people from a group of information users, and it is easy for people to reject digital information. Members-only listservs are an example for systems that exclude the general public while spyware technology is an 
example for rejectability of information. It follows that information can be a public good when all criteria are met, but it is not necessarily a public good in organisations.

An interesting perspective by Fulk et al. (1996) presents information as a hybrid (neither private nor public) good, where public benefit is achieved by individuals or companies acting out of their private interests. Patents are an example of a hybrid good, where an assignee's private interests are protected while yielding benefits to the public by the publication of the invention. In fact, with patents personal gain is the driver to achieve the contribution to the public. Another example is academic articles which are published - thanks to the interests of researchers - but ultimately they provide the advantage to the general public by advancing science and informing people. A similar sentiment is offered by Connolly and Thorn (1990) who proposed privatisation as a solution to the public goods problem, and by Jarvenpaa and Staples (2001) who brought up the term "shared ownership" of information by the individual and the organisation.

If information in sharing situations were a public good, we would expect the problem of free riding to occur. In the next section we present an analysis of free riding leading to the conclusion that free riding should not be a problem for information-sharing systems once a critical mass of contributors has formed.

\subsection{Is free riding a problem for information sharing?}

One problem of public goods is free riding because it results in unbalanced contribution: some enthusiasts contribute while others enjoy those contributions without reciprocating. Eventually, enthusiasm will erode leading to the slowdown or even demise of the group or community. Free riding is made easy when certain participants can 'hide' by using the good without contributing. Lack of physical proximity coupled with computing power results in the common practices of false identities and multiple identities which are widely practised in the World Wide Web. False or multiple identities seem like the ideal hideout. Following the same logic, increased transparency should reduce free riding. Communication systems can help increase transparency. Although passive anonymous usage of shared information, known as 'lurking', is very convenient in electronic systems, it is not an efficient form of information collection because one reads whatever is published regardless of one's own interests. Once a person wants to seek specific help, transparency is obtained. While online systems enable false and multiple identities, this is not believed to exist within companies. It is more characteristic of public fora and chat lines.

Equity theory states that employees strive to achieve the same ratio of output to input as their colleagues (Adams, 1965). Despite the temptation to apply equity theory to electronic environments by having everyone contribute symmetrically to digital communication systems, it may not necessarily be the best mode of behaviour. Free riding may turn out to be a blessing in disguise for online communication systems connecting many to many for the following reasons:

- It is better for the group if many members free ride than if they contribute negatively (poor knowledge, unexamined sources, etc.). Negative contributions can create an intolerable overload of useless information.

- Information sought tends to be unique. A free-rider on a substantial portion of exchanges may become an active contributor in a particular question. 'Self-filtration' actually constitutes good citizenship and professional ethics in this context. 
- Free-riders are virtually invisible in online systems and tend to be ignored. They are not perceived as free-riders.

- Connectivity does not mean that everyone who is connected actually has information to contribute. Yet, these free-riders get a unique learning opportunity and can feel part of the community, generating community level positive effects (Fulk et al., 1996).

All this is based on the assumption that a critical mass of knowledgeable contributors has been achieved (Macy, 1990; Markus, 1990; Marwell and Oliver, 1993).

Combining these arguments together with people's natural tendency to share information cited earlier, it seems that free-riders are a welcome part of an online information system and do not pose a problem. Moreover, the absence of sharing has been the focus of some attention in the form of research about online reticence, silence, and lurking (Preece et al., 2004; Rafaeli et al., 2004; Kalman and Rafaeli, 2005).

\subsection{Information-sharing research - summary}

In summary, organisational information sharing is not necessarily beset by the classical problems of public goods - although information is at times, a public good. Lurking or free riding are not necessarily negative for computerised networked contexts. In fact, the degree to which silence, lurking, and free riding are prevalent and are detrimental should be the focus of further research. Other questions awaiting further research include: what are optimal community sizes for information sharing? What constitutes an appropriate level of sharing, which would sustain community without overloading it?

Information sharing can hold potential for better learning processes. Recently increased attention is devoted to learning from peers in the context of both formal and extracurricular studies and training. Here, too, the technology of discourse may aid the degree of information sharing (Barak and Rafaeli, 2004).

Table 1 summarises the research cited on information sharing in organisations. It illustrates the diversity of sources that have dealt with information sharing and the variety of theories, methodologies, and disciplinary approaches to this issue.

Table 1 Information sharing research approaches

\begin{tabular}{lll}
\hline Researchers & \multicolumn{1}{c}{$\begin{array}{c}\text { Research method } \\
\text { information sharing } \\
\text { behaviour }\end{array}$} \\
\hline $\begin{array}{l}\text { (Connolly and Thorn, 1990) } \\
\text { (Macy, 1990; Markus, 1990; }\end{array}$ & Laboratory experiment & $\begin{array}{l}\text { Free riding and } \\
\text { database-mediated sharing, } \\
\text { enhanced by privatisation }\end{array}$ \\
$\begin{array}{l}\text { (Fulk et al., 1996; Sproull et al., } \\
\text { 1996) }\end{array}$ & Theory development, survey & $\begin{array}{l}\text { Critical mass needed to } \\
\text { sustain sharing }\end{array}$ \\
$\begin{array}{l}\text { Interpersonal vs. } \\
\text { database-mediated sharing, } \\
\text { (Fulk et al., 1996; Wasco and }\end{array}$ & Theak ties \\
Faraj, 2000) & Theory development, survey & $\begin{array}{l}\text { Communication discipline } \\
\text { Communality }\end{array}$ \\
\hline
\end{tabular}


Table 1 Information sharing research approaches (continued)

\begin{tabular}{|c|c|c|}
\hline Researchers & Research method & $\begin{array}{c}\text { Theory explaining } \\
\text { information sharing } \\
\text { behaviour }\end{array}$ \\
\hline (Butler et al., in press) & Survey & Leadership \\
\hline (Constant et al., 1994) & Field experiment & Social exchange theory \\
\hline $\begin{array}{l}\text { (Jarvenpaa and Staples, 2000; } \\
\text { 2001) }\end{array}$ & Survey & Perception of ownership \\
\hline (Adar and Huberman, 2000) & $\begin{array}{l}\text { Analytic modelling and } \\
\text { empirical log analysis }\end{array}$ & Free riding \\
\hline (Kiesler et al., 2000) & Field experiment & Level of knowledge \\
\hline $\begin{array}{l}\text { (Kolekofski and Heminger, } \\
2003 \text { ) }\end{array}$ & Survey & Theory of reasoned action \\
\hline (Cummings, 2004) & Survey & Group structural diversity \\
\hline (Barron and Yechiam, 2002) & Field experiment & Diffusion of responsibility \\
\hline (Raban, 2004a) & Laboratory experiment & Perception of ownership \\
\hline $\begin{array}{l}\text { (Preece et al., 2004; Ravid and } \\
\text { Rafaeli, 2004; Kalman and } \\
\text { Rafaeli, 2005) }\end{array}$ & $\begin{array}{l}\text { Survey and empirical log } \\
\text { analysis }\end{array}$ & $\begin{array}{l}\text { Incidence and causes of } \\
\text { nonsharing, silence and } \\
\text { lurking }\end{array}$ \\
\hline (Barak and Rafaeli, 2004) & Field experiment & $\begin{array}{l}\text { System structure impact in } \\
\text { the context of learning }\end{array}$ \\
\hline (Rafaeli and Ravid, 2003) & Laboratory experiment & $\begin{array}{l}\text { System structure impact in } \\
\text { the context of business } \\
\text { decisions }\end{array}$ \\
\hline
\end{tabular}

Table 2 summarises a list of factors that serve to promote or hinder sharing. Some of these have received attention in the literature while others are speculative and await further research. Obviously, each factor can be discussed as promoting or hindering sharing depending on the circumstances. This table attempts to show the common effects of the various factors and complements Table 1 by including additional factors as well as by defining variables for research.

Table 2 Factors that promote or hinder information sharing online and variables for further research

\begin{tabular}{lll}
\hline $\begin{array}{l}\text { Factors that promote } \\
\text { information sharing online }\end{array}$ & $\begin{array}{c}\text { Factors that hinder } \\
\text { information sharing online }\end{array}$ & \multicolumn{1}{c}{ Variables for research } \\
\hline Ownership & Public goods - free riding & Broadcasting vs. sharing \\
Personal benefits: self & Diffusion of responsibility & Ownership/privatisation \\
identity/respect/esteem & Organisational culture and & Seeking vs. sharing \\
Prior acquaintance and & politics & Information vs. advice \\
similarity & Hierarchical organisational & Validation of benchmark \\
Prosocial transformation & structure & Cause or solution for \\
Social facilitation & Competition & information overload \\
Reciprocity & Selfishness & Setting a common goal \\
\hline
\end{tabular}


Table 2 Factors that promote or hinder information sharing online and variables for further research (continued)

\begin{tabular}{lll}
\hline $\begin{array}{l}\text { Factors that promote } \\
\text { information sharing online }\end{array}$ & $\begin{array}{c}\text { Factors that hinder } \\
\text { information sharing online }\end{array}$ & \multicolumn{1}{c}{ Variables for research } \\
\hline Organisational citizenship and & Alienation & Using a confederate \\
norms & Self-inefficacy in the subject & Various organisational settings \\
mesignating a community & & $\begin{array}{l}\text { Availability of for-fee } \\
\text { information }\end{array}$ \\
leader & & $\begin{array}{l}\text { Use of complementary } \\
\text { technologies }\end{array}$ \\
Having a common goal & & Mediated vs. interpersonal \\
'Small World' community & sharing \\
structure & \\
Technology usability & \\
Information system design & & \\
Incentives & & \\
Trust & & \\
\hline
\end{tabular}

\section{Information-sharing technologies}

Multiple settings and systems have evolved on the internet over the past decade to implement and realise information sharing. The technological models are as varied and confused as the business models. Years into the internet revolution there still are many different experiments but no real convergence on best practices.

The earliest known versions of online sharing environments date back to the e-mail-based discussion lists that predate the internet. Implemented in the form of listservs, majordomo and other centralised hub implementers of group email, these early interpretations leveraged collections of e-mail addresses and allowed a limited form of group consultation. Theoretical discussions of social translucence and interactional coherence (Erickson et al., 1999; Herring, 1999) addressed these early forms, and the dynamics of sharing information on such fora.

Usenet and IRC were the next generation. (See Sudweeks et al. (1996) for discussion of the information exchange dynamics on Usenet. See Danet et al. (1996) for a discussion of the dynamics on IRC). IRC was a global level expression of large-scale group synchronous discussion. A large number of these are in-effect information sharing interactions. Usenet is still very much in use despite its somewhat antiquated connotation. For example, in 2001 an average of about 700,000 messages were contributed to Usenet per day with many of those messages being replies to previous postings (Viegas and Smith, 2004). See http://netscan.research.microsoft.com for fresh data on Usenet transactions.

The WWW protocol introduced in the early '90s along with the CGI modifications allowed for the creation of many more web-based fora for information sharing. Web-based systems allowed much more intricate and sophisticated designs while appealing to a much larger audience. Now, the not necessarily technically oriented were invited into online exchanges and sharing as well. Added to the archive, subject tree, time stamp and the thread were many additional affordances including colour, sound, animation, cookies, cross linking and hypertext. More importantly, the web environment 
created identifiable loci, brands, and highlighted the role of individual participant and group. Thus, for example, while Microsoft maintains numerous technical support, information sharing groups on Usenet, few if any of the participants in these groups have a sense of belonging or allegiance to them. On the web, on the other hand, many hundreds of thousands of informal interest groups maintain their own information exchange meeting places.

In the first few years of the 21 st century, the web evolved into a new stage, with the emergence of 'blogs'. Blogs are online tools that enable personal management of continuously evolving online content. They have become very popular, and are maintained by millions of individuals. Sophisticated aggregation and measurement tools, such as Blogdex, Daypop, Popdex, and Technorati have developed to assist in exploring, mapping, tracking, and mining this gushing fountain of subjective observations and facts. Personal blogs gave birth to group blogs, where even more information exchange takes place. Group blogs such Plastic.com, Metafilter.com, Slashdot.org and the like are vibrant information sharing loci with a character. Character can be of the individual or group maintaining the site. It can also be corporate. In this context it is worth mentioning web-based information sharing localities such as GoogleAnswers.com, TheStraightDope.com, Abuzz.com. Some argue that blogs are fuelled by a 'reputation economy'. People maintain personal blogs and are active in group blogs motivated by a quest for recognition and status. Other theories question the simplicity of this observation, noting that interest in community allegiance, expression and the presentation of self play no less of a role (see, for instance Allen in http://www.lifewithalacrity.com) and Shirky in (http://www.corante.com/many/). Reputation leads to recommender systems, a more automated form of information sharing. Reputation systems are gaining popularity. More famous forms include such as Amazon's system for books, and EBay's system that collects and displays vouching for buyers and sellers. See Masum and Zhang (2004), Dellarocas and Resnick (2003) and Beenen et al. (2004) for discussion of the dynamics on these systems.

So called 'Wikis' are server-based software systems that allows users to freely create and edit web page content using any Web browser. Wiki supports hyperlinks and has a simple text syntax for creating new pages and crosslinks between internal pages on the fly. Wikis are designed to enable 'open editing', encourage democratic use of the Web and promote content composition by nontechnical users. The proliferation of wiki-powered information collections, including encyclopedias and dictionaries is impressive.

Among the latest innovations in online mechanisms that encourage information sharing are the social networking online tools for charting and exploiting individuals' friends, relatives, and acquaintances - a person's 'personal network.' These networks can then branch out and allow friends to connect with people inside their accepted social circle, harnessing a perceived increase in trust. Social networking has emerged as a phenomenon in 2003, allowing the newly populous internet to serve as both a buffer and a safety net for introduction to friends by friends once possible only in person. LinkedIn.com, Friendster.com, Orkut.com are among the more heavily populated of these sites. A database of many of these is kept here: https://www.quickbase.com/db/9f72vfgx?a=q\&qid=1. The mapping of social network of interaction on the internet is a logical extension of the blog and Instant Messaging (IM) phenomena: blogs allow for a more community of personal inquiry and thought while IM 
systems allow for only accepted users to chat. There are hybrids, however, such as the concept of FriendBlogs, which combines social networking with blogging.

So far in this section we provided a chronological and technological narrative. The more interesting story to tell is that of the business proposition faced by or presented to prospective information sharers. Work along these lines produced innovations such as Hanson's Idea Futures (Hanson, 1995), The Iowa Electronic Markets (http://www.biz.uiowa.edu/iem/), Harnad's Skywriting (Harnad, 1990) etc.

The proliferation of information-sharing systems and environments is yet another strong indicator of the basic need for sharing information. It also indicates that, as we have said in the introduction to this review, information sharing is not uniform. There are various levels and options for sharing and therefore this issue invites much academic research to establish 'best practices' by gaining a deeper theoretical understanding of the underpinnings of this behaviour. The abundance of technological alternatives for sharing information also indicates that while technology is freely available, information itself is social (Brown and Duguid, 2000) and the extent of sharing is socially constructed (Fulk et al., 1995).

\section{Summary}

The information-sharing continuum ranging from the free flow of gossip to the highly restricted flow of specialised and proprietary information has been explored by research from various schools of thought, using a variety of methods. However, we do not yet have a clear theoretical framework to explain this vast phenomenon and the behaviours leading to and emanating from it. Is information shared mostly for altruistic reasons or for external motivation? Is information that is shared valued more highly, and more likely to be trusted than purchased information? Is 'owned' information more likely to be shared? The current paper presented current research milestones and mapped the constructs that are suggested by the prevailing theories, by common sense, and by the emerging technologies and practices. We offer some directions for future research. The plethora of available systems listed here, and the audiences eager to partake in the information made available on these systems, as well as those active in making that information available, present excellent opportunities for implementing such research. In the end, all research is about information sharing.

\section{References}

Adams, J.S. (1965) 'Inequity in social exchange', in L. Berkowitz (Ed.) Advances in Experimental Social Psychology, New York: Academic Press.

Adar, E. and Huberman, B.A. (2000) 'Free riding on Gnutella', First Monday, Vol. 5, No. 10, http://firstmonday.org/issues/issue5_10/adar/index.html

Ahituv, N. and Neumann, S. (1986) Principles of Information Systems for Management, Dubuque, Wm, C. Brown Publishers.

Barabasi, A.L. (2002) Linked: The New Science of Networks. NY: Perseus.

Barak, M. and Rafaeli, S. (2004) 'Online question-posing and peer-assessment as means for web-based knowledge sharing in learning', International Journal of Human-Computer Studies, Vol. 61, No. 1, pp.84-103. 
Barron, G. and Yechiam, E. (2002) 'Private e-mail requests and the diffusion of responsibility', Computers in Human Behavior, Vol. 18, No. 5, pp.507-520.

Beenen, G., Ling, K., Wang, X., Chang, K., Frankowski, D., Resnick, P. and Kraut, R.E. (2004) 'Using social psychology to motivate contributions to online communities', Proceedings of ACM CSCW 2004 Conference on Computer Supported Cooperative Work, Chicago, IL, $\mathrm{http} / / /$ www.si.umich.edu/ presnick/papers/cscw04/cscw2004preprint.pdf

Brown, J.S. and Duguid, P. (2000) The Social Life of Information, Boston, MA: Harvard Business School Press.

Butler, B.S., Sproull, L., Kiesler, S. and Kraut, R. (in press) 'Community effort in online groups: who does the work and why?', in S. Weisband and L. Atwater (Eds.) Leadership at a Distance, Mahwah, NJ: Erlbaum.

Connolly, T. and Thorn, B.K. (1990) 'Discretionary databases: theory, data, and implications', in J. Fulk and C.W. Steinfield (Eds.) Organizations and Communication Technology, Newbury Park: Sage Publications, Inc., pp.219-233.

Constant, D., Kiesler, S. and Sproull, L. (1994) 'What's mine is ours, or is it? A study of attitudes about information sharing', Information Systems Research, Vol. 5, No. 4, pp.400-421.

Constant, D., Sproull, L. and Kiesler, S. (1996) 'The kindness of strangers: the usefulness of electronic weak ties for technical advice', Organization Science, Vol. 7, No. 2, pp.119-135.

Cummings, J.N. (2004) 'Work groups, structural diversity, and knowledge sharing in a global organization', Management Science, Vol. 50, No. 3, pp.352-364.

Danet, B., Ruedenberg-Wright, L. and Rosenbaum-Tamari, Y. (1996) 'Hmmm...Where's that smoke coming from? Writing, play and performance on internet relay chat', Journal of Computer-Mediated Communication, Vol. 2, No. 4, $\mathrm{http}: / /$ www.ascusc.org/jcmc/vol2/issue4/danet.html

Davenport, T.H. and Prusak, L. (1998) Working Knowledge: How Organizations Manage What They Know, Boston, Massachusetts: Harvard Business School Press.

Dellarocas, C. and Resnick, P. (2003) 'Online reputation mechanisms: a roadmap for future research', MIT/NSF Interdisciplinary Symposium on Reputation Mechanisms, Boston, MA, http://ccs.mit.edu/dell/symposium.html

Dixon, N.M. (2000) Common Knowledge: How Companies Thrive by Sharing What They Know, Boston, Massachusetts: Harvard Business School Press.

Dunbar, R.I.M. (1996) Grooming, Gossip, and the Evolution of Language, Cambridge, MA: Harvard University Press.

Erickson, T., Smith, D.N., Kellogg, W.A., Laff, M., Richards, J.T. and Bradner, E. (1999) 'Socially translucent systems: social proxies, persistent conversation, and the design of "babble", Proceedings of the SIGCHI Conference on Human Factors in Computing Systems: The CHI is the Limit, Pittsburgh, PA.

Fulk, J., Flanagin, A.J., Kalman, M.E., Monge, P.R. and Ryan, T. (1996) 'Connective and communal public goods in interactive communication systems', Communication Theory, Vol. 6, No. 1, pp.60-87.

Fulk, J., Schmitz, J. and Ryu, D. (1995) 'Cognitive elements in the social construction of communication technology', Management Communication Quarterly, Vol. 8, No. 3, pp.259-288.

Hanson, R. (1995) 'Idea futures', Wired, Vol. 3, No. 9, http://www.wired.com/wired/archive/3.09/hanson.if.html

Harnad, S. (1990) 'Scholarly skywriting and the prepublication continuum of scientific inquiry', Psychological Science, Vol. 1, pp.342-343.

Herring, S.C. (1999) 'Interactional coherence in CMC', Journal of Computer-Mediated Communication, Vol. 4, No. 4, http://www.ascusc.org/jcmc/vol4/issue4/herring.html

Jarvenpaa, S.L. and Staples, D.S. (2000) 'The use of collaborative electronic media for information sharing: an exploratory study of determinants', Journal of Strategic Information Systems, Vol. 9, Nos. 2-3, pp.129-154. 
Jarvenpaa, S.L. and Staples, D.S. (2001) 'Exploring perceptions of organizational ownership of information and expertise', Journal of Management Information Systems, Vol. 18, No. 1, pp.151-183.

Jones, Q., Ravid, G. and Rafaeli, S. (2004) 'Information overload and the message dynamics of online interaction spaces: a theoretical model and empirical exploration', Information Systems Research, Vol. 15, No. 2, pp.194-210.

Kalman, Y. and Rafaeli, S. (2005) 'Email chronemics: unobtrusive profiling of response times', HICSS 38, Hawaii.

Karau, S. and Williams, K. (1993) 'Social loafing: a meta-analytic review and theoretical integration', Journal of Personality and Social Psychology, Vol. 65, pp.681-706.

Kiesler, S., Zdaniuk, B., Lundmark, V. and Kraut, R. (2000) 'Troubles with the internet: the dynamics of help at home', Human-Computer Interaction, Vol. 15, No. 4, pp.323-352.

Kolekofski, K.E. and Heminger, A.R. (2003) 'Beliefs and attitudes affecting intentions to share information in an organizational setting', Information \& Management, Vol. 40, No. 6, pp.521-532.

Latane, B. and Darley, J.M. (1968) 'Group inhibition of bystander intervention in emegencies', Journal of Personality and Social Psychology, Vol. 10, pp.215-221.

Latane, B. and Rodin, J. (1969) 'A lady in distress: inhibiting effects of friends and strangers on bystander intervention', Experimental Social Psychology, Vol. 5, pp.189-202.

Lawrence, S. and Giles, L.C. (1999) 'Accessibility of information on the web', Nature, Vol. 400, pp.107-109.

Ledyard, J.O. (1995) 'Public goods: a survey of experimental research', in J.H. Kagel and A.E. Roth (Eds.) The Handbook of Experimental Economics, Princeton: Princeton University Press, pp.111-194.

Levitan, K.B. (1982) 'Information resources as "goods" in the life cycle of information production', Journal of the American Society for Information Science, January, pp.44-54.

Macy, M.W. (1990) 'Learning theory and the logic of critical mass', American Sociological Review, Vol. 55, pp.809-826.

Markus, L.M. (1990) 'Toward a "critical mass" theory of interactive media', in J. Fulk and C.W. Steinfield (Eds.) Organizations and Communication Technology, Newbury Park: Sage Publications, Inc., pp.194-217.

Marwell, G. and Oliver, P. (1993) The Critical Mass in Collective Action: A Micro-Social Theory, New York: Cambridge University Press.

Masum, H. and Zhang, Y.C. (2004) 'Manifesto for the reputation society', First Monday, Vol. 9, No. 7, http://firstmonday.org/issues/issue9_7/masum/index.html

Odlyzko, A.M. (2001) 'The public library of science and the ongoing revolution in scholarly communication', Nature Web Forum, Future E-Access to the Primary Literature, $\mathrm{http}: / / \mathrm{www}$.nature.com/nature/debates/e-access/Articles/odlyzko.html

Preece, J., Nonnecke, B. and Andrews, D. (2004) 'The top 5 reasons for lurking: improving community experiences for everyone', Computers in Human Behavior, Vol. 2, No. 1, in press.

Raban, D.R. (2004a) 'Ownership and subjective value in the trading and sharing of information', Graduate School of Business, Haifa: University of Haifa.

Raban, D.R. (2004b) 'An experimental investigation of information sharing', AoIR Conference 5.0, UK: Brighton.

Rafaeli, S. (1989) 'Soapware: the fit between software and advertising', Information and Software Technology, Vol. 31, No. 5, pp.268-275.

Rafaeli, S. and LaRose, R.J. (1993) 'Electronic bulletin boards and "public goods" explanations of collaborative mass media', Communication Research, Vol. 20, No. 2, pp.277-297.

Rafaeli, S. and Ravid, G. (2003) 'Information sharing as enabler for the virtual team: an experimental approach to assessing the role of electronic mail in disintermediation', Information Systems Journal, Vol. 13, pp.191-206. 
Rafaeli, S., Ravid, G. and Soroka, V. (2004) 'De-lurking in virtual communities: a social communication network approach to measuring the effects of social and cultural capital', 37th Annual HICSS Conference (Hawaii International Conference on System Sciences), Hawaii: IEEE Computer Society.

Ravid, G. and Rafaeli, S. (2004) 'A-synchronous discussion groups as small world and scale free networks', First Monday, Vol. 9, No. 9, $\mathrm{http} / / /$ firstmonday.org/issues/issue9_9/ravid/index.html

Raymond, E.S. (2001) The Cathedral and the Bazaar: Musings on Linux and Open Source by an Accidental Revolutionary, Cambridge, MA: O'Reilly.

Shapiro, C. and Varian, H.R. (1999) Information Rules: A Strategic Guide to the Network Economy, Boston: Harvard Business School Press.

Sproull, L., Subramani, M., Kiesler, S., Walker, J.H. and Waters, K. (1996) 'When the interface is a face', Human-Computer Interaction, Vol. 11, No. 5, pp.97-124.

Sudweeks, F., McLaughlin, M. and Rafaeli, S. (1996) Network and Netplay: Virtual Groups on the Internet, Cambridge, MA: AAAI/MIT.

Viegas, F.B. and Smith, M. (2004) 'Newsgroup crowds and authorlines: visualizing the activity of individuals in conversational cyberspaces', Proceedings of the 37th Hawaii International Conference on System Sciences, Hawaii.

Wasco, M.M. and Faraj, S. (2000) 'It is what one does: why people participate and help others in electronic communities of practice', Journal of Strategic Information Systems, Vol. 9, Nos. 2-3, pp.155-173. 